\title{
Designing health professional education curricula using systems thinking perspectives
}

\author{
Priya Khanna, Chris Roberts ${ }^{*}$ [D and Andrew Stuart Lane
}

\begin{abstract}
Background: Medical students navigate complex personal learning pathways from entry into medical school, through an educational program, and into life-long practice. However, many stakeholders have called for substantive reforms in contemporary curricula, citing concerns about the lack of key abilities amongst newly graduated doctors to work in complex healthcare environments. Despite the need for educators to focus on curricula design, there is a paucity of overarching perspectives that allow synthesis of the various curricular elements in a way that lends meaningfulness and appreciation to the students in terms of navigating the immediate program requirements and beyond. Without such guidance, educators risk creating fragmented program designs that can lead to both unintended and unactionable outcomes for students as well as curriculum designers. Using systems thinking, we set out to address this gap by providing an overarching perspective for curriculum designers to appreciate the relationships and the interactions of the various curricular elements that inform and impact student's preparedness for practice.

Methods: By framing a curriculum as a complex adaptive system, we used soft systems thinking to develop an initial prototype of a conceptual curricular toolkit, underpinned by an appraisal of relevant literature within health professional education and the broader educational context. The prototype was further refined iteratively after critical reflection by the authors with a diverse range of national and international colleagues via posters, short communications, and workshops at several conferences, and through social media.
\end{abstract}

Results: We describe how the 3P-6Cs toolkit captures a learner's personal journey through an educational program into a field of practice by logically linking the three key elements: the personal, the program, and the practice. We demonstrate its application in three examples related to contemporary health profession education curricula. These are: creating integrated educational designs to capture students' developmental continua, conceptualising immersive clinical placements in non-traditional settings, and complexity-consistent evaluation of curricular interventions.

Conclusion: Applying the 3P-6Cs curricular toolkit to problems of curricula (re)design can provide overarching perspectives that enable educators to have a better understanding of how integration of elements within education programs can inform and impact student's preparation for lifelong practice.

Keywords: Curriculum, Educational design, Education, Systems thinking, Complexity

* Correspondence: christopher.roberts@sydney.edu.au

Sydney Medical School, University of Sydney, Sydney, New South Wales,

Australia

C C The Author(s). 2021 Open Access This article is licensed under a Creative Commons Attribution 4.0 International License, which permits use, sharing, adaptation, distribution and reproduction in any medium or format, as long as you give appropriate credit to the original author(s) and the source, provide a link to the Creative Commons licence, and indicate if changes were made. The images or other third party material in this article are included in the article's Creative Commons licence, unless indicated otherwise in a credit line to the material. If material is not included in the article's Creative Commons licence and your intended use is not permitted by statutory regulation or exceeds the permitted use, you will need to obtain permission directly from the copyright holder. To view a copy of this licence, visit http://creativecommons.org/licenses/by/4.0/ The Creative Commons Public Domain Dedication waiver (http://creativecommons.org/publicdomain/zero/1.0/) applies to the data made available in this article, unless otherwise stated in a credit line to the data. 


\section{Background}

On their journey through medical school into practice as independent healthcare clinicians, present day students navigate various curricular landscapes that are becoming increasingly progressive and complex. With healthcare practice rapidly evolving to adapt to changing disease patterns and service models, medical curricula have also evolved over time, leading to contemporary models that largely focus on achieving the competencies required to work in healthcare environments [1]. Inspite of the well documented intended learning outcomes within sophisticated blueprints, a lack of key abilities amongst newly graduated medical students still persists [2], leading to increasing calls for reforms in medical education programs, particularly in curriculum design [3]. Contemporary curricular reforms, both in undergraduate as well as postgraduate settings, are mostly targeted towards reforming individual elements of a program such as vertical integration of basic and clinical sciences; competency-based learning outcomes, and programmatic and entrustable task-based approaches to assessments. The resultant curricular blueprints, although based on sound educational perspectives to fostering and assessing graduate competencies, are complex to conceptualise and challenging to implement. Without an explicit reference to and inclusion of the 'big picture' elements of practice that goes beyond the program they are enrolled into, students may struggle with sensemaking in relation to their learning trajectory $[4,5]$.

In a hypothetical but plausible scenario, a beginning first-year medical student is left in awe as she reads the curriculum handbook of a medical school that has recently renewed its curriculum in the light of contemporary approaches to learning and assessment. Although appreciating the sophisticated design, she does seem lost in the complex labyrinth of educational jargon. The student finds herself trying to decipher the basics: what does she need to learn; what and where are the learning activities to be undertaken, and when and how will she be assessed? The student's journey of learning, however, does not conclude with graduation but continues as she joins the community of practice of clinicians in the healthcare workforce. A challenging task for the curriculum designers therefore, is to ascertain coherence of various curricular elements while ensuring that their educational utility is appreciated beyond the immediate program requirements by both learners and educators.

A gap, however, persists in relation to overarching curriculum perspectives that allow for synthesis of the various curricular elements in a way that lends coherence and meaningfulness to all stakeholders, particularly students. The paucity of synthetic and overarching curricular perspectives can be inferred from the literature that broadly suggests two key models that underpin medical program curricula: prescriptive and descriptive models [6]. Contemporary approaches to redesigning medical education curricula are largely outcomes-based approaches that emphasise the functional capabilities to be acquired by graduates at the end of a medical program [7]. Such approaches are based on prescriptive models of curriculum as their emphasis is more on the ends rather than the means of the curricular process [6]. Proponents of prescriptive curricular models, such as competencybased approaches, believe them to be intuitive and promising in mitigating challenges for new graduates in negotiating the contemporary healthcare landscape. Critics, however, have highlighted the risks associated with the outcome-based approaches at the conceptual, assessment, and practical levels [8] including tendencies to reductionism and oversimplification of complex capabilities and critical skills such as professional judgement [9]. Although not as widespread as prescriptive models, there have been attempts towards more descriptive models of curriculum development such as Skilbeck's situational model [10] and Pinar et al's curriculum reconceptualization theory, and more recently, the symbiotic curricular model. An example of this is the PRISMS model (product focused'; 'relevant'; 'inter-professional'; 'shorter, smaller'; 'multi-site'; and 'symbiotic') that aims to guide curricular designs in building and reinforcing relationships between medical schools and healthcare services [11]. However, these are not as widespread as the prescriptive models, and they do not inform how different components of the curriculum will work in unison to capture the learning trajectory as the student progresses within a particular program in order to practise in evolving healthcare models and practices $[6,12]$.

Exploring the natural history of a curriculum from design to implementation can indicate major changes in the original philosophy and rationale, resulting in a fragmented approach, with differing curricular elements being underpinned by differing learning theories [13, 14]. Curricular designs in the present day and age, therefore, need a more holistic approach that takes into account intersections and interrelations between the programlevel curricular elements and the larger contexts of practice-level subsystems whilst keeping in view learner's developmental progression in core capabilities. A coherent and overarching theoretical approach underpinning complex curricular blueprints will ensure the integrity of a whole of curriculum approach [15].

A substantial shift in thinking is therefore required from conceiving of a curriculum as a single mechanical entity that can be 'fixed' by attending to individual elements towards understanding the ecology of how various intersecting and interrelating curricular components impact a learner's trajectory from being an individual student to becoming a member of a community of practice. 
Such a conceptual shift for curriculum designers can be provided by systems thinking. Regarded as a synergistic thinking toolkit, systems thinking aims to understand the interrelationships, dependencies, and interactions shaping the dynamics of the various elements within and across various levels of systems and sub systems [1517]. It is considered as a highly relevant perspective to understand, predict and improve the capabilities of complex adaptive systems such as a curriculum [18]. In this paper, using systems thinking as a theoretical referent, we aim to provide curriculum designers with a thinking toolkit that enables educators as well as learners in understanding how the various components of a curriculum can be better designed to capture a learners' journey as they traverse along program-level requirements while keeping in sight preparedness for practice in rapidly evolving complex healthcare settings. By the term 'thinking toolkit', we mean a set of ideas, perspectives and approaches, informed by soft systems thinking, that will enable educators to visualise, create, improve, implement, and evaluate new or existing curricular designs.

\section{Methodology}

We developed an initial prototype of an overarching curricular toolkit by undertaking an appraisal of relevant literature in curricular designs for complex systems, especially with reference to using a systems thinking approach. This approach was taken given the authors' familiarity with this field, and commitment to a curricular design process that avoided the risk of a fragmented approach by focusing on individual curricular subsystems and multiple learning theories [14]. The prototype was further refined iteratively after critical reflection by the authors with a diverse range of national and international colleagues via posters, short communications, and workshops at several conferences, and through social media.

\section{Conceptual framework}

Our framework was guided by various systems thinking perspectives [19-21] wherein interactions between various systems and subsystems can be analysed in terms of boundaries, relationships, and perspectives between and within various systemic elements. By the term 'system' we take the view of Checkland, [21] that a system is an adaptive whole that can survive and thrive despite the shocks and alarms of inevitable environmental change. In framing curriculum as an adaptive system, each learning subsystem will be properly linked to others allowing for an appropriate flow of information for self-regulation and adaptation to contextual influences. Only by understanding the ecology of the concepts that constitute the system, can we promote balance between the whole and its parts [19]. This 'soft-system' approach is in contrast to the 'hard systems' approach that assumes a linear representation of the real world, albeit a reductionist one. Our view of systems thinking conforms with a 'soft systems' approach as a way of generating both engagement with, and insight about, the real world and allows for the different ways in which the different stakeholders may frame similar curricular issues or problems. Soft system thinking has been regarded as an appropriate approach for high-level structuring of a 'messy' real-world problem situation. While the hard system approach informs how a system and its subsystems work, a soft systems approach describes why a system works the way it does [21-24]. It is an holistic approach to understand how various components of a sub-system intersect, interrelate, and interact within the context of larger systems [23, 25].

With these theoretical underpinnings in mind, we conceptualised a thinking toolkit, '3P-6Cs' (Fig. 1) that illustrates a student's journey through interactions and intersections of various curricular elements at the personal $\left(\mathrm{P}_{1}\right)$, program $\left(\mathrm{P}_{2}\right.$ with $\left.6 \mathrm{Cs}\right)$, and practice $\left(\mathrm{P}_{3}\right)$ levels. The personal describes core considerations of learning at the level of an individual learner; the program describes the features or elements of a curriculum, both the explicit and hidden, that a learner navigates through; and the practice describes the wider context for learning within the clinical workforce.

Our conceptual toolkit is overarching in the sense that it is akin to an umbrella approach that provides a big picture under which several sub-approaches or models can be sheltered and aligned based on their commonalities [26].

\section{The personal level}

At the personal level, the student begins her journey at the start of the medical program by reflecting on the core personal considerations of learning - what is to be learnt (Content), how to learn (Cognition), and selfassessing that what should be learnt has been learnt (Confirmation). Confirmation of learning (from self and program assessments) will be a major driver of her learning, but other strategies can foster adaptive skills such as reflexivity and metacognition [18]. At a personal level, there may be negotiation of the boundaries between the designed curriculum with the hidden curriculum. This negotiation will be influenced by students' intrinsic motivations, communications, and their beliefs and attitudes as they interact with agents such as peers, educators, as well as patients, and agencies such as program-level rules, structures, regulations and policies [27].

\section{The program level $6 \mathrm{Cs}$}

The program level curricular elements constitute the '6Cs' that define and connect various curricular elements within a curriculum framework. These are commands, contextualisation, coordination, collections, collations, and connections (Table 1). The first three Cs are 


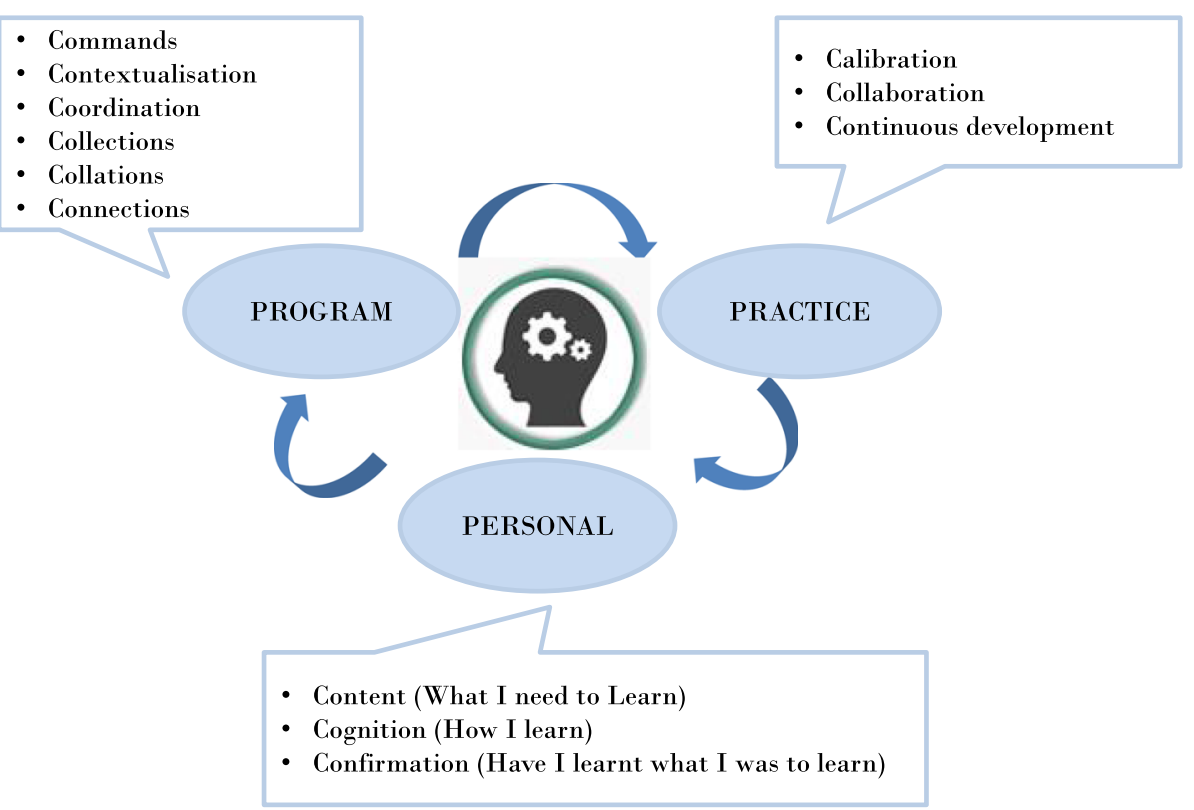

Fig. $13 \mathrm{P}-6 \mathrm{C}$ s Systems Thinking Toolkit

primarily focused on teaching and learning tasks and outcomes: Commands (e.g. learning outcomes as defined by the relevant governing bodies); Contextualisation (e.g. learning outcomes, settings and environments) and Coordination (integrating learning and teaching and settings and activities). The second three Cs are assessment-focused: Collections (marks/scores/narratives), Collations (combining differing assessments as per curricular domains or themes or competencies to inform decisionmaking and progression) and Connections (communicating results; reflections on learning and evaluation of curricula).

\section{The practice level}

The practice level elements of the thinking toolkit are focused on the big picture for graduates entering practice as one of a community of health care professionals. As the new graduates transition into their next phase of work integrated learning, our toolkit suggests three key processes: 1) fostering learners to 'calibrate' the skills, knowledge and behaviours in accordance with their new workplace requirements, and training programs to meet career intentions 2) the self-regulated and calibrated competencies would be exercised in a learning environment that is highly dependent on 'collaboration' between and within interprofessional teams, and 3) ensuring 'continual development' of lifelong learning as new graduates move from internship into further specialty training.

Table 1 The 6 Cs of teaching-learning-assessment at the program level

\begin{tabular}{|c|c|}
\hline C1: Commands & $\begin{array}{l}\text { Agencies such as university rules, policies, and procedures; accrediting body's standards and outcomes; and internship/ } \\
\text { residency frameworks that command and control the high-level vision, mission, outcomes and practices of the curricular } \\
\text { design. }\end{array}$ \\
\hline 2: Contextualisation & $\begin{array}{l}\text { Curricular themes, learning outcomes, objectives, content, learning and teaching methodologies, depth and breadth of } \\
\text { clinical exposure directed by various contextual factors such as educators, staff, students, and teaching-learning settings. }\end{array}$ \\
\hline ation & coordination \\
\hline ions & $\begin{array}{l}\text { Gathering evidence on students' developmental progression within a particular year and across all years of a program using a } \\
\text { program of assessments. }\end{array}$ \\
\hline C5: Collations & $\begin{array}{l}\text { Capturing students' progression in various competencies using collated data from various assessment points in a way that } \\
\text { facilitates triangulation, coherence, consistency, improved educational effect, and holistic judgement of students' progression } \\
\text { into the next level. }\end{array}$ \\
\hline C6: Connections & $\begin{array}{l}\text { Connections occur at multiple levels: connecting students with reflections on their performance, and empowering them to be } \\
\text { better prepared for the next training level; connecting the network of stakeholders by using their expertise in making } \\
\text { judgements about student's progressions, and connecting the 'commands' of standards for a medical program with those of } \\
\text { residency/training outcomes by ensuring students are prepared for practice. }\end{array}$ \\
\hline
\end{tabular}


As an intern, resident or consultant, a lifelong learner would need to fulfil workplace and program requirements. Therefore, personal and program level 6C curricular elements are also at work at the practice level (given learners will undergo a new training program at this level), albeit the focus will be shifted towards calibrated, collaborative and continuous development of knowledge, skills and behaviours.

\section{IMPLICATIONS OF THE 3P-6CS SYSTEMS THINKING FRAMEWORK FOR CURRICULAR DESIGNS}

We anticipate that a systems thinking toolkit will provide educators with useful insights when redesigning whole or particular curricular elements. This can be achieved by better understanding of the relationships, boundaries and impacts of personal, program, and practice level elements nested within various curricular subsystems. By explicitly linking various curricular elements and considerations at personal, program, and practice levels, the 3P-6Cs model provides a better understanding of the ecology of curricular elements. The thinking toolkit provides a series of heuristics for educators to address key curricular concerns such as: how to help students make sense of underlying curricular blueprints, and helping them see the big picture beyond the immediate program-level concerns by addressing specific learning outcomes to develop their practice-level capabilities.

To illustrate the utility of our toolkit for health professional educators, we describe applications of the $3 \mathrm{P}-6 \mathrm{Cs}$ systems thinking toolkit in three key areas of curricular design:

1) creating integrated educational designs to capture students' developmental continua,

2) conceptualising immersive clinical placements in non-traditional settings; and

3) complexity-consistent evaluation of curricular interventions.

\section{Creating a coherent and integrated curricular design to capture students' developmental continua}

Several healthcare professional programs are aspiring towards competency or outcomes-based frameworks that aim to capture the developmental continua of students in milestones or standards of performance in various competencies and sub-competencies [28]. Such a program requires a synthetic and agile design that can meaningfully triangulate complex knowledge, skills and behaviours sampled across various clinical contexts, activities and assessments $[15,22]$. An example of the utility of the program level 6Cs to capture students' progression within a curriculum using a program of learning-teaching-assessments is demonstrated in Fig. 2. Expanding the concept of Bigg's constructive alignment [29], the program level 6Cs facilitate the following: constructive alignment of external 'commands' that direct program-level learning outcomes with 'contextualisation' of outcomes and learning methods keeping in view the local flavour in which the program is embedded; and 'coordination' of competencies and outcomes with learning-teaching-settings and and learning activities. For example, in our example (Fig. 2) there is a focus on case -based learning. The 'collection' of information on students' progression in various curricular competencies can be meaningfully captured longitudinally using a system of assessment comprising relevant data tools and assessment rubrics (illustrated as matrices for written, work-based and group tasks in Fig. 2). These collections are then meaningfully 'collated' within an assessment record, for example, within a portfolio or program of assessments, in our example (Fig. 2) around three vertical themes of knowledge, skills, and professional behaviours. These are communicated to form 'connections 'for students, faculty and program designers: for students to connect the gaps in their learning when reflecting on their achievements, and for faculty to reflect on the educational impact of tasks, assessments, and progression decisions. Finally, for program designers to reflect on how well the various elements of the curriculum were constructively aligned.

\section{Conceptualising immersive clinical placements designs in non-traditional settings}

Several medical education programs, as well as other healthcare disciplines, are now offering early and varied clinical immersion by providing placements beyond traditional hospital settings, such as in general practice, ambulatory care, and allied healthcare settings. There is ample and robust evidence for the benefits of early exposure to nonhospital based settings, not only for students in improving a diverse range of skills for the holistic care of patients, but for the medical school in terms of improving graduate outcomes for the program, and establishing a community of diverse preceptors. At the practice level, such immersions can facilitate in bridging the general practitionerspecialist divide as well as the doctor-allied healthcare practitioner divide in providing collaborative patient centred care [30, 31].

Keeping in view these benefits of diverse clinical exposure at the personal, program and practice levels, the $3 \mathrm{P}-6 \mathrm{Cs}$ can guide design considerations for an authentic learning task-based curriculum that can bridge the gap between education needs (immediate program requirements) and 


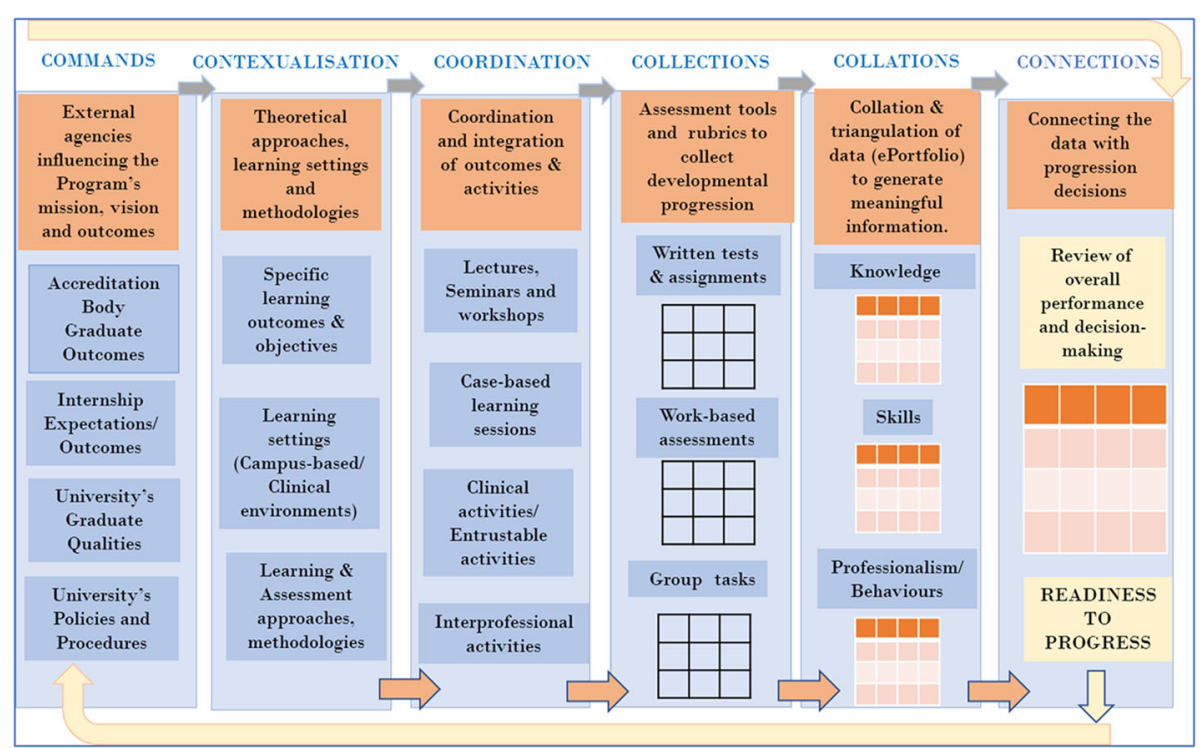

Fig. 2 Application of 6Cs to create a coherent and integrated curricular design

service needs (creating a community of diverse practices and practitioners) (Fig. 3).

By applying the $3 \mathrm{P}-6 \mathrm{Cs}$, educators can facilitate in bringing the key stakeholders together in order to workshop the important principles of an immersive clinical placement. This may include the contextualisation of the overarching learning outcomes, collecting observations and feedback of student learning behaviour in the community, developing a community of practice of committed educators, and building capacity in practices offering placements.

\section{Designing complexity-consistent evaluation frameworks}

Curricula are complex adaptive systems and curricular interventions are complex in themselves [3]. Evaluative inquiry into the impact of interventions in such complex systems involves the quality of being systemic, which is not just the property of the system but also of the methodological 'lenses' through which one looks into understanding how and why a system works the way it does. For complex interventions, such a systems-based approach can guide research and evaluation paradigms and

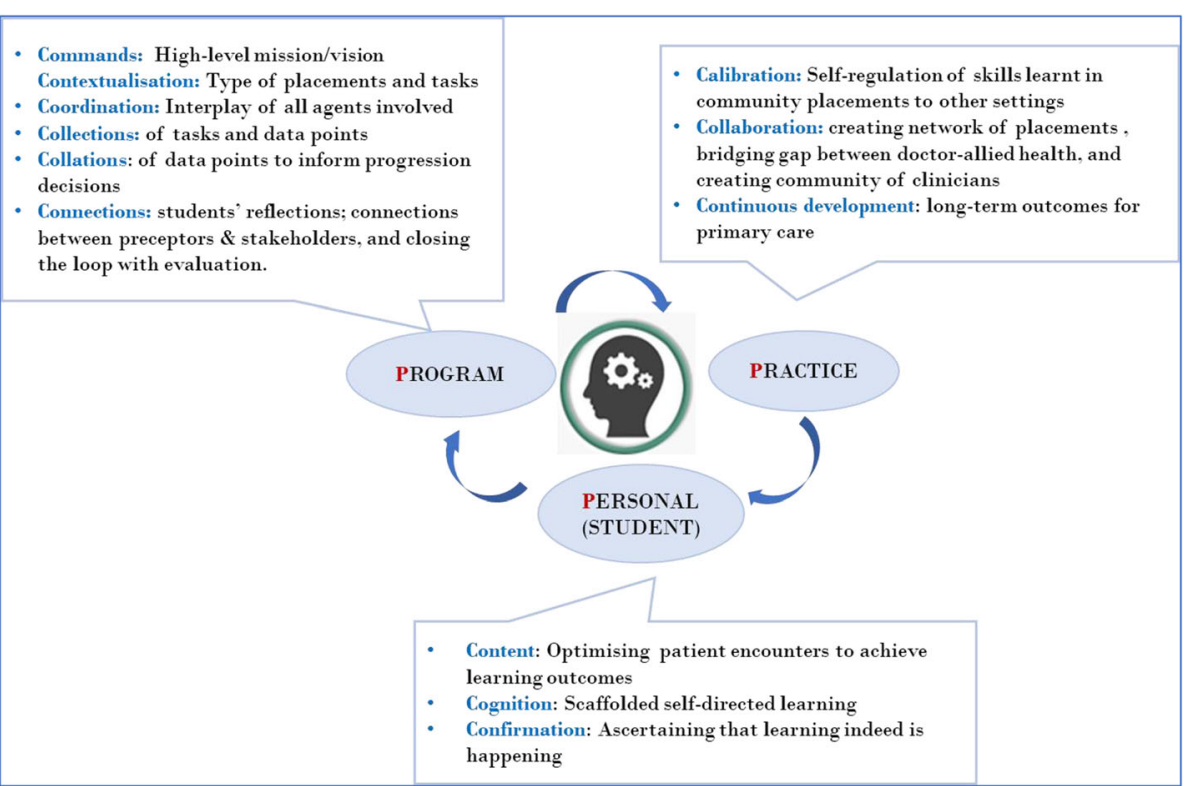

Fig. 3 Applying 3P-6Cs in creating coherent mini-curriculum for immersive clinical placements 
enable in formulating appropriate program theories to better predict program interventions and outcomes. Such a complexity consistent worldview, as offered by systems thinking, is appropriate to evaluate curricular interventions where we wish to know not only whether a curricular intervention works, but why or why not, for whom, and in what context. Systems thinking seems to be commensurable with theory-driven approaches such as realist evaluation frameworks that are deemed suitable to evaluate health professional education curricular interventions [32]. More specifically in terms of $3 \mathrm{P}-6 \mathrm{Cs}$, the personal, program, and practice level considerations can help educators collect and utilise rich data on why, where, and for whom the redesigned curriculum is working or not working, identify the underlying mechanisms and propose possible solutions to fix the problems.

With the evolving complexity of healthcare settings and delivery, there is a well acknowledged shift to systems-based practice ('how can we improve the system of care'). Systems thinking provides a toolkit that fosters the understanding of interdependencies, interactions, and interrelations across and within any system. It is, therefore, the cornerstone of systems-based practice, and has been regarded as one of the core competencies for clinicians $[17,33]$. We propose that this toolkit of system thinking has the potential to lay the foundations for a systems-based curriculum that is, a curriculum that better captures interrelations and intersections of a student's journey towards systems-based practice in the service of patient care.

\section{Conclusion}

Applying the 3P-6Cs curricular toolkit to problems of curricula redesign can provide overarching perspectives that enable educators to have a better understanding of how integration of elements within medical education programs can impact students' preparation for lifelong practice. It aims to capture linkages between various elements of the curricular landscape as a students traverse from the personal to program to practice levels. Based on thinking systemically (thinking in terms of systems) and applying a systems approach to the critical issues of future patient care, we anticipate that the $3 \mathrm{P}-6 \mathrm{Cs}$ will provide a parsimonious yet coherent thinking toolkit to foster better understanding of the relationships, boundaries, perspective and dependencies of various learning subsystems within a curriculum. Our curricular toolkit provides mechanisms for healthcare professional education curricula to evolve, both in their approach and methods, towards improved alignment with individual components of the training continuum, and with the needs of healthcare systems and the patients which the graduates of the program will serve.

\section{Abbreviations}

3P- 6Cs: The system thinking toolkit described in this article; Ps: Personal, Program, and Practice; 6Cs: Refer to the program level curricular elements of commands, contextualisation, coordination, collections, collations, and connections

\section{Acknowledgements}

None.

\section{Authors' contributions}

PK conceived of the systems thinking approach to curriculum development and wrote the first draft. PK, CR and SL were involved in appraising the literature, framework building, applying and refining the prototype 3P-6Cs framework to various curricula problems derived from their extensive experience, and extensively revising the manuscript. All authors have read and approved the final manuscript.

\section{Funding}

No funding was received for this paper.

\section{Availability of data and materials}

This paper describes the application of systems thinking to curriculum design. It is not an empirical study. There are no data to share.

Ethics approval and consent to participate

No ethics were required for this paper.

\section{Consent for publication}

No applicable.

\section{Competing interests}

Chris Roberts is a section editor of BMC Medical Education. Priya Khanna and Stuart Lane have no competing interests to declare.

Received: 14 May 2020 Accepted: 10 December 2020

Published online: 06 January 2021

\section{References}

1. Holmboe ES. Competency-based medical education and the ghost of Kuhn: reflections on the messy and meaningful work of transformation. Acad Med. 2018;93(3):350-3.

2. Monrouxe LV, Bullock A, Gormley G, Kaufhold K, Kelly N, Roberts CE, Mattick K, Rees C. New graduate doctors' preparedness for practice: a multistakeholder, multicentre narrative study. BMJ Open. 2018;8(8):e023146.

3. Jorm C, Roberts C. Using complexity theory to guide medical school evaluations. Acad Med. 2018;93(3):399-405.

4. Lomis KD, Russell RG, Davidson MA, Fleming AE, Pettepher CC, Cutrer WB, Fleming GM, Miller BM. Competency milestones for medical students: design, implementation, and analysis at one medical school. Medical teacher. 2017;39(5):494-504.

5. Storrar N, Hope D, Cameron H. Student perspective on outcomes and process-recommendations for implementing competency-based medical education. Medical Teacher. 2019;41(2):161-6.

6. Prideaux D. Curriculum design.( $A B C$ of learning and teaching in medicine). Br Med J. 2003;326(7383):268-71.

7. Frank JR, Snell LS, Cate OT, Holmboe ES, Carraccio C, Swing SR, Harris P, Glasgow NJ, Campbell C, Dath D, Harden RM, lobst W, Long DM, Mungroo $\mathrm{R}$, Richardson DL, Sherbino J, Silver I, Taber S, Talbot M, Harris KA. Competency-based medical education: theory to practice. Med Teacher 2010;32(8):638-45.

8. Touchie C, ten Cate O. The promise, perils, problems and progress of competency-based medical education. Med Educ. 2016:50(1):93-100.

9. Lee A, Steketee C, Rogers G, Moran M. Towards a theoretical framework for curriculum development in health professional education. Focus Health Prof Educ Multi-Disciplin J. 2013:14(3):70

10. Pinar WF, Reynolds WM, Slattery P, Taubman PM. Understanding curriculum: An introduction to the study of historical and contemporary curriculum discourses, Vol. 17: Peter Lang; 1995.

11. Bligh J, Prideaux D, Parsell G. PRISMS: new educational strategies for medical education. Med Educ. 2001;35(6):520-1. 
12. Bleakley A. The curriculum is dead! Long live the curriculum! Designing an undergraduate medicine and surgery curriculum for the future. Med Teach. 2012;34(7):543-7.

13. Norman G. The birth and death of curricula. Springer. 2017.

14. Bowe CM, Armstrong E. Assessment for systems learning: a holistic assessment framework to support decision making across the medical education continuum. Acad Med. 2017;92(5):585-92.

15. McKimm J, Jones PK. Twelve tips for applying change models to curriculum design, development and delivery. Med Teach. 2018;40(5):520-6.

16. Arnold RD, Wade JP. A definition of systems thinking: a systems approach. Proc Comput Sci. 2015;44(2015):669-78.

17. Plack P, Margaret M, Scott R. Systems thinking in the healthcare professions: a guide for educators and clinicians; 2019

18. Quirk $\mathrm{M}$, Chumley $\mathrm{H}$. The adaptive medical curriculum: a model for continuous improvement. Med Teach. 2018:40(8):786-90.

19. Cabrera D, Colosi L, Lobdell C. Systems thinking. Eval Program Plann. 2008; 31(3):299-310

20. Ackoff RL. Systems thinking and thinking systems. Syst Dyn Rev. 1994;10(23):175-88.

21. Checkland P. Four conditions for serious systems thinking and action. Syst Res Behav Sci. 2012;29(5):465-9.

22. Pourdehnad J, Wexler ER, Wilson DV. Integrating systems thinking and design thinking. Syst Thinker. 2011;22(9):2-6

23. Reynolds M, Holwell S. Introducing systems approaches. In: Systems approaches to managing change: A practical guide. edn.: Springer; 2010. p. $1-23$.

24. Železnik D, Kokol P, Vošner HB. Adapting nurse competence to future patient needs using Checkland's soft systems methodology. Nurse Educ Today. 2017:48:106-10.

25. Waldman J. Thinking systems need systems thinking. Systems Research Behav Science. 2007;24(3):271-84.

26. Aldridge J, Kuby P, Strevy D. Developing a metatheory of education. Psychol Rep. 1992;70(3):683-7.

27. Wright SR, Boyd VA, Ginsburg S. The hidden curriculum of compassionate care: can assessment drive compassion? Acad Med. 2019;94(8):1164-9.

28. Holmboe ES, Salzman DH, Goldstein JL, McGaghie WC. Mastery Learning, Milestones, and Entrustable Professional Activities. In: Comprehensive Healthcare Simulation: Mastery Learning in Health Professions Education. edn.: Springer; 2020. p. 311-30

29. Biggs J. Enhancing teaching through constructive alignment. High Educ. 1996;32(3):347-64.

30. Dornan T, Littlewood S, Margolis SA, Scherpbier A, Spencer J, Ypinazar V. How can experience in clinical and community settings contribute to early medical education? A BEME systematic review. Medical teacher. 2006;28(1):3-18.

31. Roberts C, Daly M, Kumar K, Perkins D, Richards D, Garne D. A longitudinal integrated placement and medical students' intentions to practise rurally. Med Educ. 2012;46(2):179-91.

32. Haji F, Morin MP, Parker K. Rethinking programme evaluation in health professions education: beyond 'did it work?'. Med Educ. 2013;47(4):342-51.

33. Johnson JK, Miller SH, Horowitz SD. Systems-based practice: improving the safety and quality of patient care by recognizing and improving the systems in which we work. In: Advances in patient safety: new directions and alternative approaches (Vol 2: culture and Redesign). edn.: Agency for Healthcare Research and Quality (US); 2008.

\section{Publisher's Note}

Springer Nature remains neutral with regard to jurisdictional claims in published maps and institutional affiliations.

\section{Ready to submit your research? Choose BMC and benefit from:}

- fast, convenient online submission

- thorough peer review by experienced researchers in your field

- rapid publication on acceptance

- support for research data, including large and complex data types

- gold Open Access which fosters wider collaboration and increased citations

- maximum visibility for your research: over $100 \mathrm{M}$ website views per year

At BMC, research is always in progress.

Learn more biomedcentral.com/submissions 